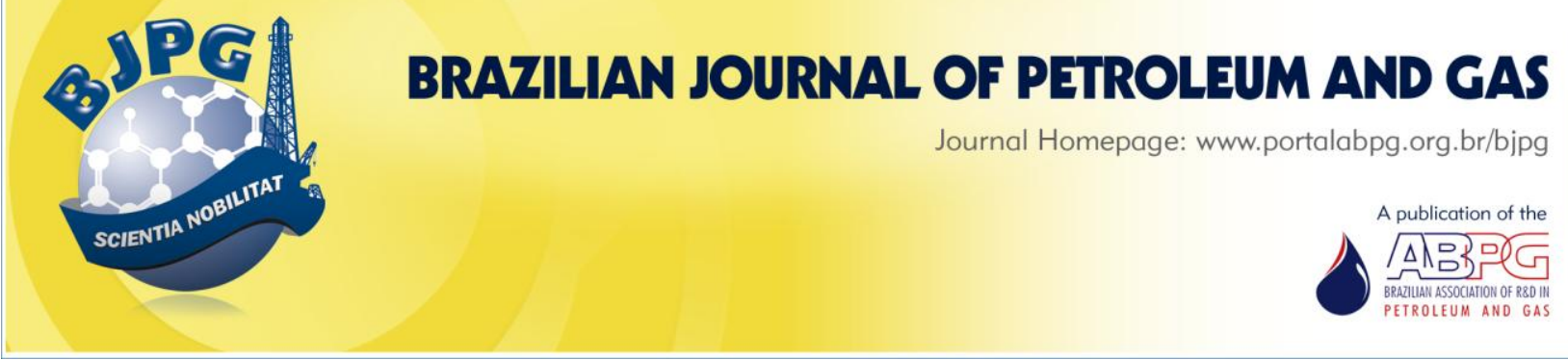

\title{
PURIFICATION OF HYDROGEN RICH GAS BY MEANS OF CO REMOVAL OVER CUO-CeO ${ }_{2}$ CATALYSTS
}

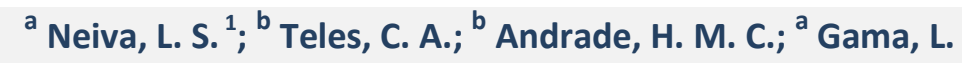 \\ ${ }^{a}$ Federal University of Campina Grande - Academic Unit of Materials Engineering \\ ${ }^{b}$ Federal University of Bahia, Chemistry Institute
}

\begin{abstract}
In this work, catalytic systems based on $\mathrm{CuO}-\mathrm{CeO}_{2}$ were synthesized using the Pechini method. These catalytic systems were applied in the PROX process. In the synthesis procedure, the $\mathrm{CuO}-\mathrm{CeO}_{2}$ catalytic systems were synthesized with 0.1 and $0.5 \mathrm{~mol}$ of $\mathrm{CuO}$. The $\mathrm{CuO}_{-} \mathrm{CeO}_{2}$ catalytic systems were characterized by XRD with refinement by the Rietveld method, chemical analysis by EDX, morphological analysis by SEM, textural analysis, agglomerates size distribution, analysis of thermogravimetric data, and catalytic tests at bench scale in the PROX reaction. According to the results, the concentrations of $\mathrm{CuO}(0.1$ and $0.5 \mathrm{~mol}$ ) inserted in the $\mathrm{CuO}-\mathrm{CeO}_{2}$ catalytic system showed great influence on the structural characteristics observed in the X-ray diffraction results. However, morphologic and textural features and the results of agglomerates size distribution did not show significant changes to the variation of CuO concentration inserted in the catalytic systems developed in this work by the Pechini method. According to the catalytic tests, both synthesized samples were ready to be applied in a process of converting $\mathrm{CO}$ to $\mathrm{CO}_{2}$. However, the sample containing $0.1 \mathrm{~mol}$ of $\mathrm{CuO}$ was more active than the catalyst sample containing $0.5 \mathrm{~mol}$ of the same catalytic active species.
\end{abstract}

\section{KEYWORDS}

$\mathrm{CuO}-\mathrm{CeO}_{2}$ catalytic system; Pechini method; $\mathrm{CO}$ removal; PROX process

\footnotetext{
${ }^{1}$ To whom all correspondence should be addressed.

Address: Federal University of Campina Grande - Academic Unit of Materials Engineering, Aprígio Veloso Avenue, 882, Campina Grande (PB), Brazil

CEP: 58109-970| e-mail: Isoutoneiva@yahoo.com.br

doi:10.5419/bjpg2011-0010
} 


\section{INTRODUCTION}

The interest in cerium oxide $\left(\mathrm{CeO}_{2}\right)$ has increased in the past decade because it plays a vital role in emerging technologies for environmental and energy-related applications (Qiang et al., 2007). Among a variety of oxides, cerium oxide $\left(\mathrm{CeO}_{2}\right)$ is particularly interesting to several catalytic processes. For instance, ceria has been used as catalyst or support in selective oxidation, synthesis of fine chemicals, methane steam reforming, phenol hydrogenation at atmospheric pressure, and solid oxide fuel cell applications (Tang et al., 2004).

One of the important applications of ceria is its use in environmental catalysis, particularly in the design of the new generation of three-way catalysts for simultaneously controlling NO, CO, and hydrocarbon emissions in oxygen-rich conditions. This happens because ceria has a large capacity to store oxygen and an ability to transfer bulk oxygen to its surface quickly (Sedmark et al., 2004). The former may uptake oxygen under fuellean conditions and the latter may release oxygen under reducing conditions, allowing a ceriacontaining catalyst to efficiently work in a relatively wide window of oxygen partial pressure. In addition, ceria may also improve metal dispersion on it and promote surface and bulk oxygen reducibility of the support when used as catalysts additive (Liu et al., 2004).

In recent years, numerous research efforts have focused on finding and developing a catalyst suitable to selectively oxidize $\mathrm{CO}$ (CO removal), a process known as preferential oxidation of $\mathrm{CO}$. Such a catalyst should be active for the oxidation of $\mathrm{CO}$ and inactive for the undesired oxidation of $\mathrm{H}_{2}$, in the temperature range $80-250{ }^{\circ} \mathrm{C}$. Supported noble metal catalysts, especially the Pt-group and Au catalysts, have been extensively studied (Wolf \& Schuth, 2002). However, the high cost of precious metals has encouraged researchers around the world to look for alternative catalysts. In particular, it has been found that the $\mathrm{CuO}-\mathrm{CeO}_{2}$ catalytic system is highly active and exceptionally selective for the preferential oxidation of $\mathrm{CO}$ (Avgouropoulos \& loannides, 2007). A strong synergetic effect between copper and ceria has been reported to be responsible for the high activity of these catalysts compared to conventional Cu-based catalysts (Cheekatamarla et al., 2005). Furthermore, studies presented in the literature have shown that $\mathrm{Cu}$ has proved highly resistant to poisoning by carbon dioxide, water steam, and sulfur compounds also known as mercaptans (Cheekatamarla et al., 2005; Prasad \& Rattan, 2010).

Literature shows that noble metal catalysts ( $\mathrm{Au}$, $\mathrm{Pt}$, and $\mathrm{Ru}$ ) and oxide catalyst of $\mathrm{CuO}-\mathrm{CeO}_{2}$ have been developed for the PROX process. Gold-based catalysts are active at low reaction temperature ( $80^{\circ} \mathrm{C}$ ), but their activities are seriously affected by the presence of sulfur compounds, $\mathrm{CO}_{2}$, and excessive $\mathrm{H}_{2} \mathrm{O}$ in hydrogen-rich gas (Avgouropoulos et al., 2006). Pt and $\mathrm{Ru}$ catalysts are active at medium reaction temperature $\left(\sim 140^{\circ} \mathrm{C}\right)$, but relatively low in selectivity for $\mathrm{CO}$ oxidation $(<50 \%)$. Comparably, $\mathrm{CuO}-\mathrm{CeO}_{2}$ catalysts have the advantages of low cost and high selectivity for $\mathrm{CO}$ oxidation (Triki et al., 2009).

The chemical synthesis method based on polyesters obtained from citrates was developed by Pechini (1967) and is largely used for synthesis of several polycations metallic oxides. The Pechini method is based on chelation or complexation of cations by hydroxycarboxylic acids such as the citric acid. The source of cations can be diverse. The chelation process occurs during the mixture of cations and citric acid in aqueous solution. This solution, with no particle in suspension, is mixed with a glycol such as ethylene glycol and heated up to $90-100^{\circ} \mathrm{C}$ until complete water elimination. The polymerization occurs at $120-140^{\circ} \mathrm{C}$ through the polyesterification reaction between the citrate salt and ethylene glycol. Thus, the formation of transparent solid polyester resin with no phase segregation is observed in this condition. The general idea of this method is to obtain a random distribution of cations at atomic level in a solid resin. After this stage, the polyester is decomposed to eliminate the excess of organic material and the cation is oxidized to form the desirable stoichiometric phase (Lessing, 1989).

The aim of this work is to synthesize the CuO$\mathrm{CeO}_{2}$ catalytic system applying the Pechini method. The catalytic systems developed will be submitted to various characterizations techniques for analysis of their structural features and their catalytic performance will be evaluated in the PROX reaction in bench scale. 


\section{EXPERIMENTAL}

The $\mathrm{CuO}-\mathrm{CeO}_{2}$ catalytic systems were synthesized by the Pechini method using the following precursors: citric acid, cerium nitrate, copper nitrate, and ethylene glycol, all with high purity. Initially, a solution composed by distilled water, nitrates (sources of metal ions), citric acid, and ethylene glycol was prepared under constant agitation at $70^{\circ} \mathrm{C}$. After adding all the mentioned precursors, the obtained solution was heated at the temperature of polyesterification reaction ( $120^{\circ} \mathrm{C}$ ) to form a resin. The resin formed was submitted to a pre-calcination stage $\left(\sim 400^{\circ} \mathrm{C}\right)$ to remove excess of organic matter from the ethylene glycol, generating as product a carbonized material still containing traces of organic matter. This product was crushed, sieved in a 325 mesh, and then subjected to a calcination stage at $700{ }^{\circ} \mathrm{C}$ to eliminate the remaining organic matter, and also to form the desired phase $\left(\mathrm{CuO}-\mathrm{CeO}_{2}\right)$ in a developed material structure. The final product obtained after the calcination stage was the desired catalytic system, which was sent to the characterizations stage. In this work, two catalytic systems based on $\mathrm{CuO}-\mathrm{CeO}_{2}$ were synthesized, one containing 0.1 $\mathrm{mol}$ of $\mathrm{CuO}$ and another with $0.5 \mathrm{~mol}$ of $\mathrm{CuO}$. The samples of the $\mathrm{CuO}-\mathrm{CeO}_{2}$ catalytic system containing $0.1 \mathrm{~mol}$ of $\mathrm{CuO}$ were called $\mathrm{P} 1$, and the samples of the $\mathrm{CuO}-\mathrm{CeO}_{2}$ catalytic system containing $0.5 \mathrm{~mol}$ of $\mathrm{CuO}$ were called P5.

Samples of the synthesized catalytic systems obtained were submitted to the following characterization techniques: structural analysis by X-ray diffraction (XRD) using a Shimadzu XRD 6000 diffractometer (with CuK $\alpha$ radiation, $\lambda=0.15418$ $\mathrm{nm}$ ) combined with refinement by the Rietveld method realized through the Maud software; chemical analysis by energy dispersive X-ray spectrometry (EDX) using a Shimadzu EDX-GP spectrometer; morphological analysis by means of scanning electron microscopy (SEM) in a ZEISS DSM 940 microscope; textural analysis by BET and BJH methods using $\mathrm{N}_{2}$ gas in a Quantachrome Nova 3200 analyzer; agglomerates size distribution using a CILAS 1064 LD particle size analyzer; thermogravimetric analysis performed on a TA analyzer instrument, model SDT 2960, in a temperature range between 25 and $1000{ }^{\circ} \mathrm{C}$ using a heating rate of $10^{\circ} \mathrm{C} \mathrm{min}{ }^{-1}$ and an inert atmosphere of $\mathrm{N}_{2}$. Finally, samples of the catalytic systems were tested specifically in the catalytic preferential oxidation of CO (PROX) inside a fixed-bed reactor in bench scale.

The catalytic test conditions were the following: total gas flow of $100 \mathrm{~mL}^{\mathrm{min}}{ }^{-1}$; composition of the gaseous charge processed equal to $70 \%$ of $\mathrm{H}_{2}, 1 \%$ of $\mathrm{O}_{2}, 1 \%$ of $\mathrm{CO}$, and $28 \%$ of $\mathrm{He}$; the temperature range of the test ranged from 50 to $210^{\circ} \mathrm{C}$ at intervals of $40^{\circ} \mathrm{C}$. For this catalytic evaluation, it was used $100 \mathrm{mg}$ of each synthesized catalyst sample. The conditions of pretreatment of the samples were the following: $300^{\circ} \mathrm{C}$ for 1 hour in an atmosphere of $30 \mathrm{~mL} \cdot \mathrm{min}^{-1}$ Helium flow. The reaction effluents were analyzed on a gas chromatograph Perkin Elmer Clarus 500, using a capillary column Carboxen ( $30 \mathrm{~m} \times 0.32 \mathrm{~mm}$ ).

\section{RESULTS AND DISCUSSION}

Figure 1 shows the X-ray patterns of the data collected before, referential or theoretical, and after, refined, the Rietveld refinement referring to $\mathrm{CuO}-\mathrm{CeO}_{2}$ catalytic systems synthesized by the Pechini method defined as P1 and P5. According to the $\mathrm{X}$-ray patterns referring the $\mathrm{P} 1$ sample, it was observed that it is possible to synthesize $\mathrm{CuO}-\mathrm{CeO}_{2}$ catalytic system with $0.1 \mathrm{~mol}$ of $\mathrm{CuO}$ and to produce crystalline $\mathrm{CeO}_{2}$ as a single phase, ie, it is possible to obtain the desired structure without the presence of segregated phases, normally $\mathrm{CuO}$, utilizing the Pechini method. The X-ray patterns referring to the P5 sample show that the concentration of $0.5 \mathrm{~mol}$ of $\mathrm{CuO}$ was sufficient to favor the presence of the $\mathrm{CuO}$ segregated phase in the structure of the $\mathrm{CuO}-\mathrm{CeO}_{2}$ catalytic system.

The structural characteristics determined by means of the Rietveld method for the $\mathrm{CuO}-\mathrm{CeO}_{2}$ catalytic systems synthesized by the Pechini method are shown in Table 1. According to the quantification of the phases formed in the analyzed structures, one can affirm that the predominant phase in both catalytic systems (P1 and P5) is the ceria phase $\left(\mathrm{CeO}_{2}\right)$. In the structure of the P1 sample containing $0.1 \mathrm{~mol}$ of $\mathrm{CuO}$ it was not possible to detect the presence of the $\mathrm{CuO}$ segregated phase. On the other hand, the P5 sample containing $0.5 \mathrm{~mol}$ of $\mathrm{CuO}$ presented the CuO segregated phases in its structure with a mass percentage of $14 \%$. This is an indication that a concentration of $0.1 \mathrm{~mol}$ of $\mathrm{CuO}$ lies within of the 

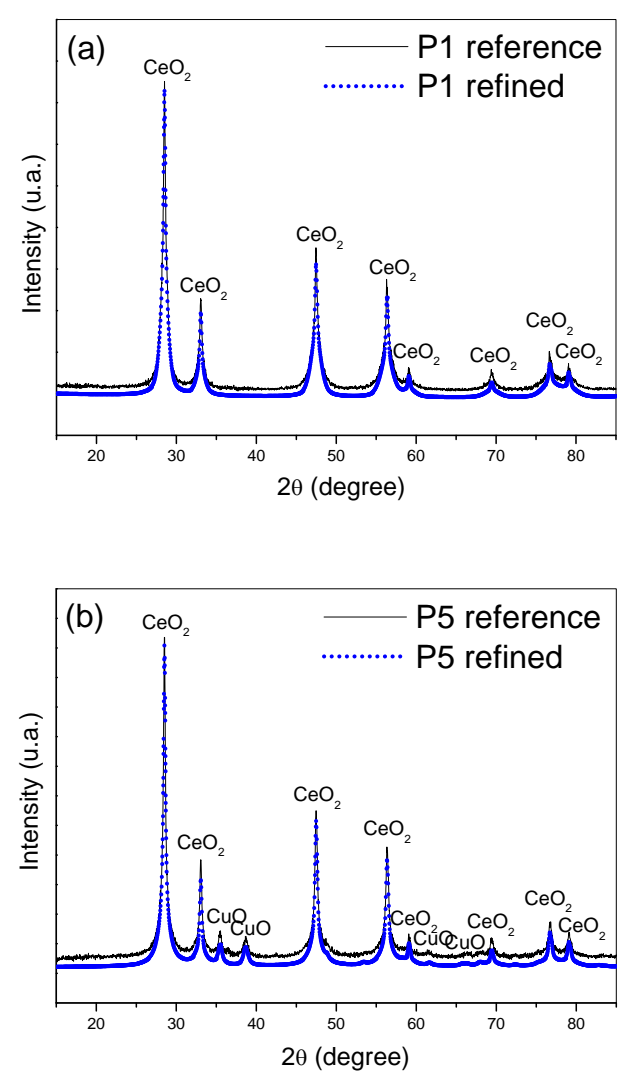

Figure 1. X-ray diffraction patterns before and after the Rietveld refinement for the P1 (a) and P5 (b) catalytic systems synthesized by the Pechini method.

solubility limit of the $\mathrm{CeO}_{2}$ atomic structure which, in this case, acts as a host matrix structure. It was also observed in Table 1 that both catalytic systems synthesized in this work enabled the formation of two types of major phases in their structures, both composed of $\mathrm{CeO}_{2}$, but with different crystallites sizes. This difference in the crystallites sizes is a consequence of the calcination step at $700{ }^{\circ} \mathrm{C}$ used in the synthesis procedure as part of the Pechini method. The calcination step promotes the

Table 1. Results of the quantification of the phases and other structural characteristics determined by the Rietveld method for the P1 and P5 catalytic systems synthesized by the Pechini method.

\begin{tabular}{ccccc}
\hline Samples & Phase & $\begin{array}{c}\text { Crystalline } \\
\text { system }\end{array}$ & $\begin{array}{c}\text { Percentage } \\
\text { mass (\%) }\end{array}$ & $\begin{array}{c}\text { Crystallite } \\
\text { size (nm) }\end{array}$ \\
\hline P1 & $\mathrm{CeO}_{2}$ & cubic & 70.3 & 13.3 \\
& $\mathrm{CeO}_{2}$ & cubic & 29.7 & 65.5 \\
P5 & $\mathrm{CeO}_{2}$ & cubic & 48.1 & 7.3 \\
& $\mathrm{CeO}_{2}$ & cubic & 37.9 & 55.5 \\
& $\mathrm{CuO}$ & monoclinic & 14.0 & 20.6 \\
\hline
\end{tabular}

coalescence of some crystals to form larger crystals and, thus, the final product can present phases composed by the same oxide but with different crystallites sizes. The phases formed in the structure of the P5 catalytic system belong to different crystal systems (cubic and monoclinic) as can be seen in Table 1.

The chemical analysis results determined by the EDX technique is presented in Table 2, which shows that the $\mathrm{CuO}-\mathrm{CeO}_{2}$ catalytic systems synthesized by the Pechini method are predominantly composed by $\mathrm{CeO}_{2}$ and $\mathrm{CuO}$. However, the presence of $\mathrm{ZnO}$ and $\mathrm{NiO}$ into the catalytic systems was detected, which were probably incorporated into the catalytic systems either by means of contaminants present in the reagents, containers, or ovens used in the synthesis procedure, or during the handling of these samples in the EDX analysis. The percentage of loss on ignition (LOI) was determined at the temperature of $1000^{\circ} \mathrm{C}$.

Table 2. Chemical composition determined by the EDX technique for the P1 and P5 catalytic systems synthesized by the Pechini method.

\begin{tabular}{cccccc}
\hline Samples & $\mathrm{CeO}_{2}$ & $\mathrm{CuO}$ & $\mathrm{ZnO}$ & $\mathrm{NiO}$ & LOI \\
& (\%) & (\%) & (\%) & (\%) & (\%) \\
\hline P1 & 90.97 & 7.89 & 0.18 & 0.12 & 0.84 \\
P5 & 65.67 & 33.41 & 0.23 & 0.09 & 0.60 \\
\hline
\end{tabular}

Figure 2 illustrates the results of morphological evaluation performed by scanning electron microscopy (SEM) in the $\mathrm{CuO}-\mathrm{CeO}_{2}$ catalytic systems synthesized by the Pechini method. The micrographs below show their respective images with magnification of 30,000 times.

According to the micrographs showed in Figure 2 , the $\mathrm{CuO}-\mathrm{CeO}_{2}$ catalytic systems synthesized by the Pechini method presented a strong tendency to the state of particle agglomeration, forming structures that are noticeably more porous. This morphology aspect is very appropriate from the point of view that potential catalytic properties are expected for these materials. It is worth pointing out that these catalytic systems present a relatively homogeneous size distribution of agglomerates. Since no significant differences were observed between the morphological characteristics presented by the P1 and P5 catalytic systems, it can be said that the incorporation process of the $\mathrm{CuO}$ in different concentrations $(0.1$ and $0.5 \mathrm{~mol})$ did 

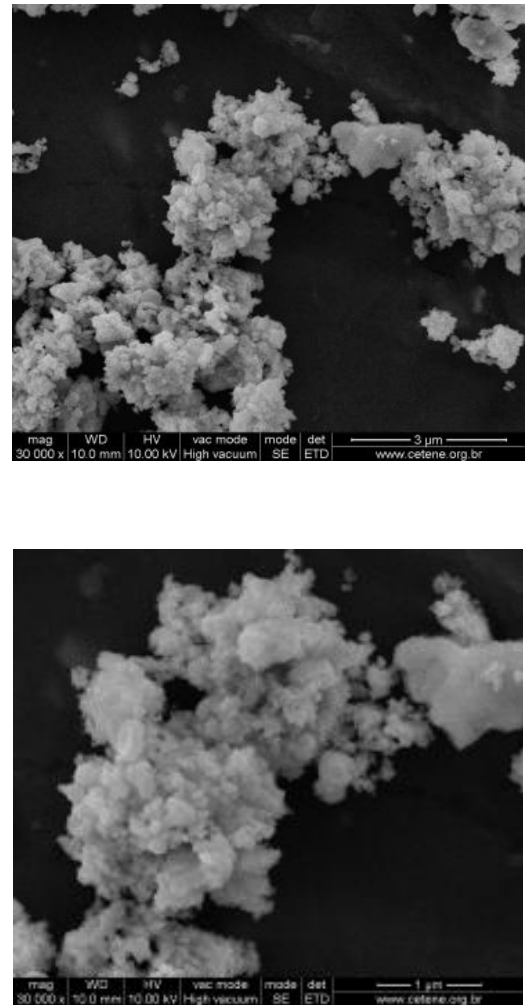

Figure 2. Micrographs obtained by SEM showing the morphology of the P1 and P5 catalytic systems synthesized by the Pechini method.

not alter the morphological characteristics of these materials. Similar morphological characteristics were found in several other studies related to the preparation of the cerium dioxide for application in catalytic reactions by different synthesis methods (Polato et al., 2005; Sun et al., 2007; Triki et al., 2009).

Figure 3 shows the $\mathrm{N}_{2}$ adsorption-desorption isotherms referring to the textural analysis of the $\mathrm{CuO}-\mathrm{CeO}_{2}$ catalytic systems synthesized by the Pechini method. According to the IUPAC classification (Sing et al., 1985), these isotherms can be classified as type III, characterizing porous materials with a predominantly macroporous nature. The H3-type hysteresis loop presented by

Table 3. Specific area, pore volume, and medium pore diameter determined for the P1 and P5 catalytic systems synthesized by the Pechini method.

\begin{tabular}{cccc}
\hline Samples & $\begin{array}{c}\text { Specific } \\
\text { area } \\
\left(\mathrm{m}^{2} / \mathrm{g}\right)\end{array}$ & $\begin{array}{c}\mathrm{V}_{\mathrm{p}} \\
(\mathrm{nm})\end{array}$ & $\begin{array}{c}\mathrm{D}_{\mathrm{p}} \\
(\mathrm{nm})\end{array}$ \\
\hline P1 & 16 & 0.02204 & 387 \\
P5 & 14 & 0.02251 & 383 \\
\hline
\end{tabular}

these isotherms, especially between $\mathrm{P} / \mathrm{P} 0=0.45$ and 0.95 , reveal the presence of pores generally formed by the association of non-rigid agglomerates of particles (Figueiredo and Ribeiro, 1987).

Table 3 shows the values of the textural characteristics such as specific area determined by the BET method, and values of pore volume $\left(V_{P}\right)$ and medium pore diameter $\left(D_{P}\right)$ determined by the $\mathrm{BJH}$ method, all referring to $\mathrm{CuO}-\mathrm{CeO}_{2}$ catalytic systems called P1 and P5 synthesized by the Pechini method.

According to the values presented in Table 3, the medium pore diameter $\left(D_{p}\right)$ of the $\mathrm{CuO}-\mathrm{CeO}_{2}$ catalytic systems synthesized in this work corresponds to macroporous dimensions $\left(D_{p}>50\right.$ $\mathrm{nm}$ ), confirming the porosity type revealed by the isotherms presented in Figure 3.

In Table 3, it can also be observed that the values of specific area, pore volume, and medium pore diameter did not present significant variations for the $\mathrm{CuO}$ concentrations incorporated in the synthesis of the $\mathrm{CuO}-\mathrm{CeO}_{2}$ catalytic systems ( $\mathrm{P} 1$
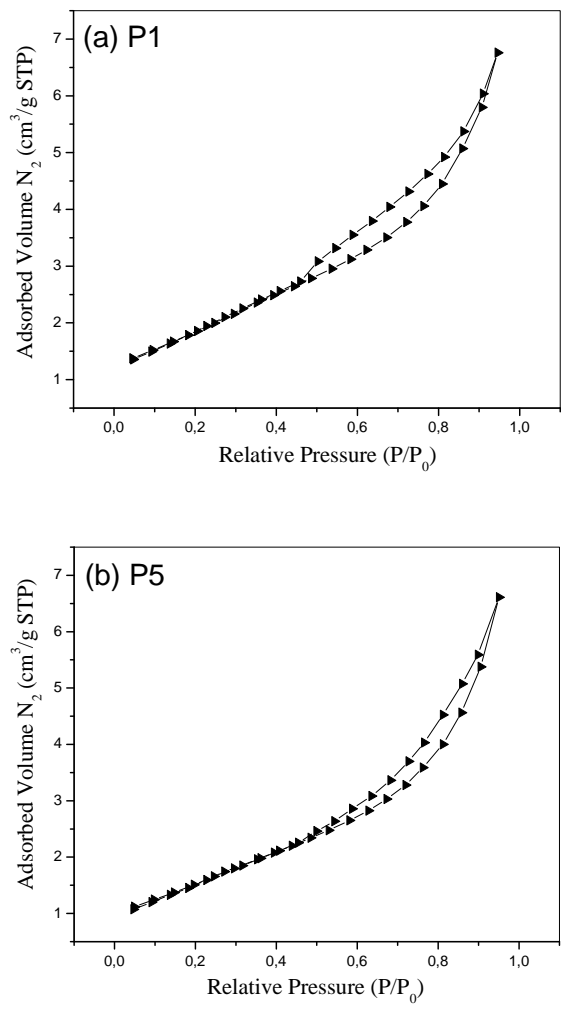

Figure 3. $\mathrm{N}_{2}$ adsorption-desorption isotherms related to the P1 (a) and P5 (b)catalytic systems synthesized by the Pechini method. 
and P5) by the Pechini method. This finding is viewed positively, considering that $\mathrm{CuO}$ was inserted into the material structure, probably causing the formation of catalytic active sites without generating great changes in the textural characteristics of the structures.

Figure 4 presents graphs of pore size distribution referring to the $\mathrm{CuO}-\mathrm{CeO}_{2}$ catalytic systems called P1 and P5 synthesized by the Pechini method.

The graphs of pore size distribution of P1 and P5 catalytic systems synthesized by the Pechini method show that these materials present full macroporous structures, as it had been revealed by the isotherms shown in Figure 3 and by the data shown in Table 3. Other researches referring to $\mathrm{CuO}-\mathrm{CeO}_{2}$ catalytic system destined for preferential oxidation of $\mathrm{CO}$ have also shown textural characteristics that are very similar to those observed for the $\mathrm{CuO}-\mathrm{CeO}_{2}$ catalytic systems obtained in this work (Moretti et al., 2008; Neiva et al., 2010).
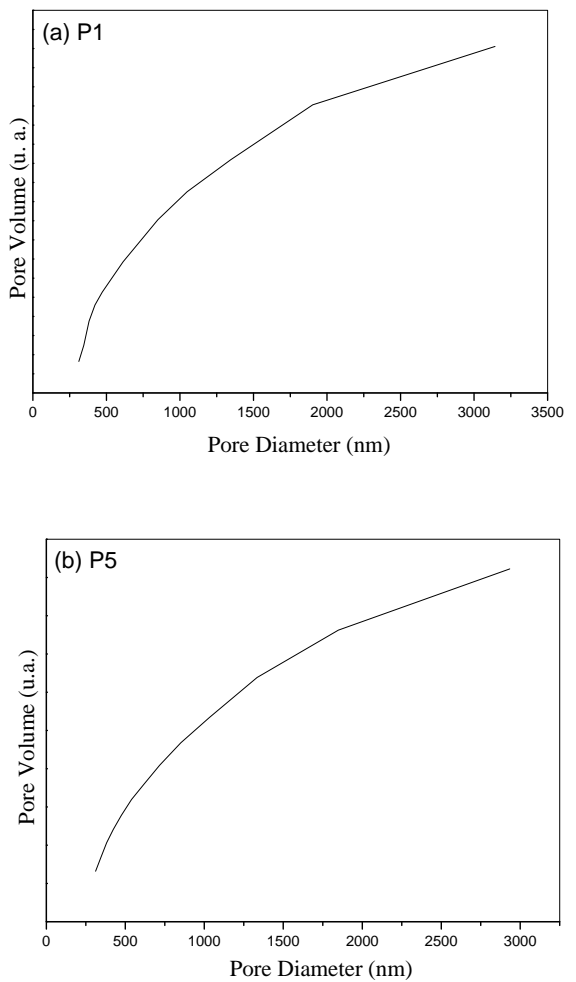

Figure 4. Graphs of pore diameter distribution of the P1 (a) and P5 (b) catalytic systems synthesized by the Pechini method.
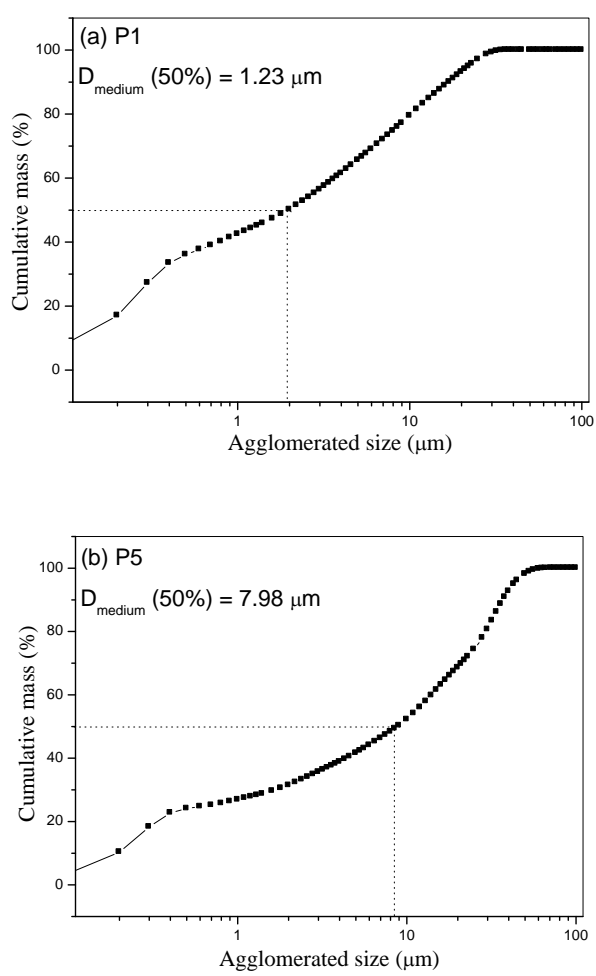

Figure 5. Agglomerates size distribution of P1 (a) and P5 (b) catalytic systems synthesized by the Pechini method.

Figure 5 shows the curves of agglomerates size distribution for P1 and P5 catalytic systems. According to Figure 5, it is possible to observe that the curves present similar profiles between the systems under study. However, the P1 catalytic system presented a lower medium diameter $\left(D_{50 \%}\right)$ of agglomerates. Thus, it is possible to affirm that the particles agglomeration capacity is directly related to the $\mathrm{CuO}$ concentration value incorporated in the structure of these materials.

According to Lima and Moreno (2009), the study of the granulometric behavior of materials composed by single or mixture oxides can lead to the determination of grain sizes suitable for use as a control parameter in specific applications of the material, with regards to the elements or substances that constitute the material as well as with the conditions of their preparation. A detailed analysis of this behavior can guarantee that more uniform and standardized products are generated.

In consonance with the thermogravimetric analysis performed on P1 and P5 samples, no weight loss were detected throughout the temperature range used ( 25 to $1000^{\circ} \mathrm{C}$ ). The 
calcination step at $700^{\circ} \mathrm{C}$, experienced by these samples during their synthesis, was certainly sufficient to eliminate any amount of organic matter and humidity.

The amount of $\mathrm{CO}$ converted to $\mathrm{CO}_{2}$ is presented in Figure 6 by means of graphic profiles of the catalytic activity of P1 and P5 samples as a function of temperature reaction. It was also recorded the percentage of $\mathrm{O}_{2}$ and $\mathrm{H}_{2}$ conversion, since these two gaseous components react with each other, so that the PROX reaction presents $\mathrm{H}_{2} \mathrm{O}$ as effluent in addition with $\mathrm{CO}_{2}$.

In Figure 6, one can observe that the activity graphic profiles of samples $\mathrm{P} 1$ and $\mathrm{P5}$ are very similar, reaching very close values of maximum percentage of activity. Sample P1 had a maximum activity of $89.18 \%$, while sample P5 showed the value of $85.63 \%$. Another similarity between the two samples is that, in both cases, the maximum conversion of $\mathrm{CO}$ occurred in the temperature range between 120 and $180{ }^{\circ} \mathrm{C}$. Even considering the similar catalytic performances of these samples, it is observed that the sample $\mathrm{P} 1$, which contains less $\mathrm{CuO}$, showed higher percentages of CO conversion. Therefore, it can be said that very
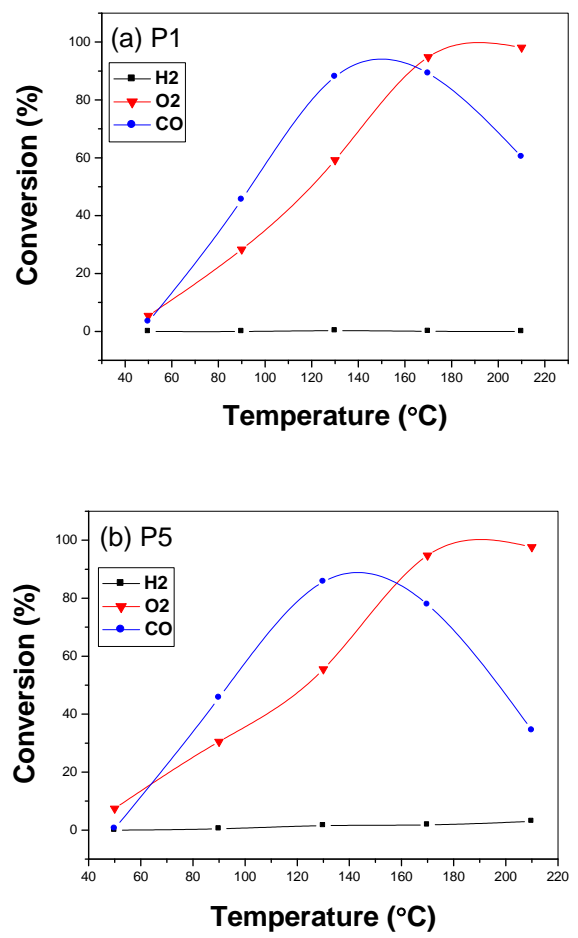

Figure 6. CO conversion as a function of temperature reaction for the catalyst samples P1 (a) and P5 (b) synthesized by the Pechini method.

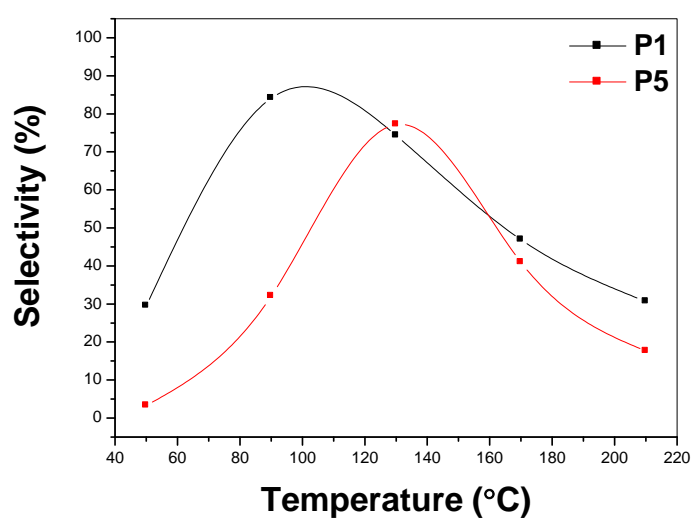

Figure 7. Selectivity for PROX reaction as a function of temperature reaction for the catalyst samples P1 and P5 synthesized by Pechini method.

high $\mathrm{CuO}$ concentrations are not necessary to achieve high rates of $\mathrm{CO}$ conversion. The explanation for this may be the fact that low concentrations allow a more homogeneous distribution of active sites, with high surface area on the structure of the catalyst, thus enhancing the catalytic performance of the material. On the other hand, relatively high concentrations of the active species can form metal clumps in the form of clusters on the structure of the material, thus leading to the formation of active sites with low contact area with the gaseous charge, minimizing the performance of the catalytic material. Other studies, also reporting on the preferential oxidation of $\mathrm{CO}$ over $\mathrm{CuO}-\mathrm{CeO}_{2}$ and $\mathrm{CuO} / \mathrm{CeO}_{2}-\mathrm{TiO}_{2}$ catalysts, found that decreasing metal content of the active species leads to increases in the rate of $\mathrm{CO}$ conversion (Maciel \& Assaf, 2010; Avgouropoulos et al., 2008).

Figure 7 shows the selectivity of samples $\mathrm{P} 1$ and P5 as a function of reaction temperatures. It can be observed that the sample P1 shows to be more selective, in that it presents higher selectivity within a broader temperature reaction range. It is understood by selectivity to PROX reaction that the capacity of this process is conducted in order to oxidize predominantly $\mathrm{CO}$ molecules, i.e., a high selectivity of the catalyst sample in the PROX reaction means that this catalyst has high ability in the oxidation process to predominantly oxidize $\mathrm{CO}$ molecules. The P1 sample was more selective and showed an activity percentile higher than the P5 one for the PROX reaction, under the studied reaction conditions. 


\section{CONCLUSIONS}

The Pechini method proved to be effective for the preparation of catalysts based on $\mathrm{CuO}-\mathrm{CeO}_{2}$ without the necessity of a step for impregnating active catalytic species. The Rietveld method was useful to identify and characterize the phases of the structures of the catalytic materials developed and to establish that the solubility limit of $\mathrm{CuO}$ in the host matrix of the $\mathrm{CeO}_{2}$ is reached at $\mathrm{CuO}$ concentrations lower than or equal to $0.1 \mathrm{~mol}$ when this oxide is incorporated into the structure of the host matrix without causing the formation of a segregated phase. The morphological and textural analysis of these catalysts revealed that the samples have porous structures formed by clusters of agglomerated particles. The analysis also shows that the pores of these structures have predominantly macroporous atomic dimensions. Catalytic assays based on the preferential oxidation reaction of $\mathrm{CO}$ (PROX-CO) showed that the sample containing $0.1 \mathrm{~mol}$ of $\mathrm{CuO}$ had the best catalytic performance, as demonstrated by the higher percentages of $\mathrm{CO}$ conversion and enhanced selectivity to $\mathrm{CO}$ during the reaction.

\section{ACKNOWLEDGMENTS}

The authors would like to thank ANP (PRH-25) for their financial and technical support for this research.

\section{REFERENCES}

Avgouropoulos, G.; Papavasiliou, J.; loannides, T. PROX reaction over $\mathrm{CuO}-\mathrm{CeO}_{2}$ catalyst with reformate gas containing methanol, Catalysis Communications, v. 9, p. 1656-1660, 2008. doi:10.1016/i.catcom.2008.01.022

Avgouropoulos, G.; loannides, T. Adsorption and reaction of $\mathrm{CO}$ on $\mathrm{CuO}-\mathrm{CeO}_{2}$ catalysts prepared by the combustion method, Catalysis Letters, v. 116, p. 15-22, 2007. doi:10.1007/s10562-007-9114-9

Avgouropoulos, G.; Papavasiliou, J.; Tabakova, T.; Idakiev, V.; loannides, T. A comparative study of ceria-supported gold and copper oxide catalysts for preferential CO oxidation reaction, Chemical Engineering Journal, v. 124, p. 41-45, 2006. doi:10.1016/i.cej.2006.08.005
Cheekatamarla, P. K.; Epling, W. S.; Lane, A. M. Selective low-temperature removal of carbon monoxide from hydrogen-rich fuels over $\mathrm{Cu}-\mathrm{Ce}-\mathrm{Al}$ catalysts, Journal of Power Sources, v. 147, p. 178183, 2005. doi:10.1016/j.jpowsour.2005.01.027

Figueiredo, J. L.; Ribeiro, F. R. Catálise Heterogênea, Ed. Fundação Calouste Gulbenkian, Lisboa, 1987. (In Portuguese)

Lessing, P. A. Mixed-cation oxide powders via polymeric precursors, Ceramic Bulletin, v. 68, n.5, p. 1002-1008, 1989.

Lima, R. H. C.; Moreno, M. M. T. Uso da distribuição granulométrica como parâmetro de controle na elaboração da massa cerâmica de composição binária, Cerâmica Industrial, v. 14, n.56, p. 34-38, 2009. (In Portuguese)

Liu, Y.; Fu, Q.; Stephanopoulos, M. F. Preferencial Oxidation of $\mathrm{CO}$ in $\mathrm{H}_{2}$ over $\mathrm{CuO}-\mathrm{CeO}_{2}$ Catalysts, Catalysis Today, v. 93-95, p. 241-246, 2004. doi:10.1016/i.cattod.2004.06.049

Maciel, C. G.; Assaf, J. M. Estudo da Reação de Oxidação Preferencial do CO sobre o Sistema $\mathrm{CuO} / \mathrm{CeO}_{2}-\mathrm{TiO}_{2}$, Química Nova, v. 33, n. 9, p. 19101914, 2010. (In Portuguese) doi:10.1590/S0100$\underline{40422010000900017}$

Moretti, E.; Lenarda, M.; Storaro, L.; Talon, A.; Montanari, T.; Busca, G.; Rodrigues-Castellón, E.; Jiménez-López, A.; Turco, M.; Bagnasco, G.; Frattini, R. One-step synthesis of a structurally organized mesoporous CuO-CeO"2-Al"2O"3 system for the preferential $\mathrm{CO}$ oxidation, Applied Catalysis A: General, v. 335, p. 46-55, 2008. doi:10.1016/j.apcata.2007.11.009

Neiva, L. S.; Leal, E.; Costa, A. C. F. M.; Mascarenhas, A. J. S.; Andrade, H. M. C.; Gama, L. Evaluation of the $\mathrm{Cu}$ dopping effects in $\mathrm{CeO}_{2}$ catalytic supports obtained by combustion reaction, Materials Science Forum, v. 660-661, p. 899-903, 2010. doi:10.4028/www.scientific.net/MSF.660-661.899

Pechini, M. P. Method of preparing lead and alkaline earth titanates and niobates and coating methods using the same to form a capacitor. U.S. Patent 3,330,697, July 11, 1967. 
Polato, C. M. S.; Henriques, C. A.; NETO, A. A.; MONTEIRO, J. L. F. Synthesis, characterization and evaluation of $\mathrm{CeO} 2 / \mathrm{Mg}$,Al-mixed oxides as catalysts for SOX removal, Journal of Molecular Catalysis A: Chemical, v. 241, p. 184-193, 2005. doi:10.1016/i.molcata.2005.07.006

Prasad, R.; Rattan, G. Preparation Methods and Applications of $\mathrm{CuO}-\mathrm{CeO}_{2}$ Catalysts: A Short Review, Bulletin of Chemical Reaction Engineering \& Catalysis, v. 5, n. 1, p. 7-30, 2010.

Qiang, G.; Meiling, W.; Yuan, L.; Xue, B. Mesoporous $\mathrm{CeO}_{2}$-Supported $\mathrm{CO}_{3} \mathrm{O}_{4}$ Catalysts for $\mathrm{CO}$ Preferential Oxidation in $\mathrm{H}_{2}$-Rich Gases, Chinese Journal of Catalysis, v. 28, n. 11, p. 953-957, 2007. doi:10.1016/S1872-2067(07)60082-5

Sedmark, G.; Hocevar, S.; Levec, J. Transient Kinetic Model of CO Oxidation Over a Nanostructured $\mathrm{Cu}_{0.1} \mathrm{Ce}_{0.9} \mathrm{O}_{2-y}$ Catalyst, Journal of $\begin{array}{lllll}\text { Catalysis, } & \text { v. 222, } & \text { p. } & \text { 87-99, } 2004 .\end{array}$ doi:10.1016/i.jcat.2003.10.006

Sing, K. S. W.; Everett, D. H.; Haul, R. A.; Moscou, W. L.; Pierotti, R. A.; Rouquerol, J.; Siemieniewska, T. Pure and Applied Chemistry, IUPAC Recommendations, v. 57, 4, 603, 1985.
Sun, C.; Li, H.; Chen, L. Study of flowerlike $\mathrm{CeO}_{2}$ microspheres used as catalyst supports for $\mathrm{CO}$ oxidation reaction, Journal of Physics and Chemistry of Solids, v. 68, p. 1785-1790, 2007. doi:10.1016/j.jpcs.2007.05.005

Tang, X.; Zhang, B.; Li, Y.; Xu, Y.; Xin, Q.; Shen, W. Carbon monoxide oxidation over $\mathrm{CuO} / \mathrm{CeO}_{2}$ catalysts, Catalysis Today, v. 93-95, p. 191-198, 2004. doi:10.1016/j.cattod.2004.06.040

Triki, M.; Ksibi, Z.; Ghorbel, A.; Medina, F. Preparation and characterization of $\mathrm{CeO}_{2}-\mathrm{TiO}_{2}$ support for Ru catalysts: Application in CWAO of $p$ hydroxybenzoic acid, Microporous and Mesoporous Materials, v. 117, p. 431-435, 2009. doi:10.1016/j.micromeso.2008.07.019

Wolf, A.; Schuth, F. A systematic study of the synthesis conditions for the preparation of highly active gold catalysts, Applied Catalysis A: General, v. 226 , p. $1-13,2002$. doi:10.1016/S0926$\underline{860 \times(01) 00772-4}$ 